\title{
A new family of donor-acceptor systems comprising tin(IV) porphyrin and anthracene subunits: Synthesis, spectroscopy and energy transfer studies
}

\author{
A ASHOK KUMAR, L GIRIBABU and BHASKAR G MAIYA* \\ School of Chemistry, University of Hyderabad, Hyderabad 500 046, India \\ e-mail:bgmsc@uohyd.ernet.in
}

\begin{abstract}
A new family of covalently linked 'Sn(IV) porphyrin-anthracene' diad (1), triad (2) and tetrad (3) donor-acceptor (D-A) systems have been designed and synthesized in good-to-moderate yields. While diad $\mathbf{1}$ possesses one anthracene subunit at the peripheral (meso) position of the tin(IV) porphyrin scaffold, triad 2 possesses two trans axial anthracene subunits at the tin(IV) centre. On the other hand, tetrad $\mathbf{3}$ is endowed with both the peripheral and axial anthracene subunits in its architecture. These D-A sy stems have been fully characterised by elemental analysis, FAB-MS, UV-Vis, ${ }^{1} \mathrm{H}$ and ${ }^{13} \mathrm{C}$ NMR and electrochemical methods. UV-Vis, NMR and redox data suggest the absence of intramolecular $\pi-\pi$ interaction between the porphyrin and the anthracene/s in 1-3. Fluorescence from the anthracene subunit in 1 and $\mathbf{3}$ is found to be quenched in comparison with the fluorescence of free anthracene in four different solvents. This is not the case with compound 2. Excitation spectral data provides evidence for an intramolecular excitation energy transfer (EET) from the singlet anthracene to the porphyrin in $\mathbf{1}$ and $\mathbf{3}$. The energy transfer efficiency is in the order: $\mathbf{2}$ (almost negligible) $<\mathbf{3}(\sim 30 \%)<\mathbf{1}$ (nearly quantitative), with the peripheral anthracene $\rightarrow$ porphyrin pathway being largely favoured. This orientation dependence of EET could be analysed using Forster's dipole dipole mechanism.
\end{abstract}

Keywords. Tin (IV) porphyrin; anthracene; spectroscopy; energy transfer; orientation dependence.

\section{Introduction}

Studies on a variety of porphyrin based donor-acceptor (D-A) assemblies have been carried out to investigate various aspects of electronic energy transfer (EET) reactions. ${ }^{1-10}$ Amongst these, a few studies have attempted to probe the orientation dependence of EET, the unequivocal demonstration of which has been elusive until we reported recently, in a preliminary communication, that it is possible to achieve the unidirectional energy transfer in a simple, porphyrin based D-A system 3. As seen in figure 1, the donor anthracene subunits in $\mathbf{3}$ are linked at both the axial and peripheral sites of a tin(IV) porphyrin scaffold. ${ }^{11}$ Fluorescence emission and excitation spectral data revealed that light absorbed by the 'peripheral' anthracene of $\mathbf{3}$ is efficiently transferred to the porphyrin but that by the 'axial' anthracene subunits is not. Consistent with this is the observation that energy transfer from the axial anthracenes in $\mathbf{2}$ is quite negligible and that from the peripheral anthracene in $\mathbf{1}$ is almost quantitative (figure 1). In the present paper, we provide details of the synthesis, spectral characterization and photophysical properties of compounds 1-3.

\footnotetext{
*For correspondence
} 

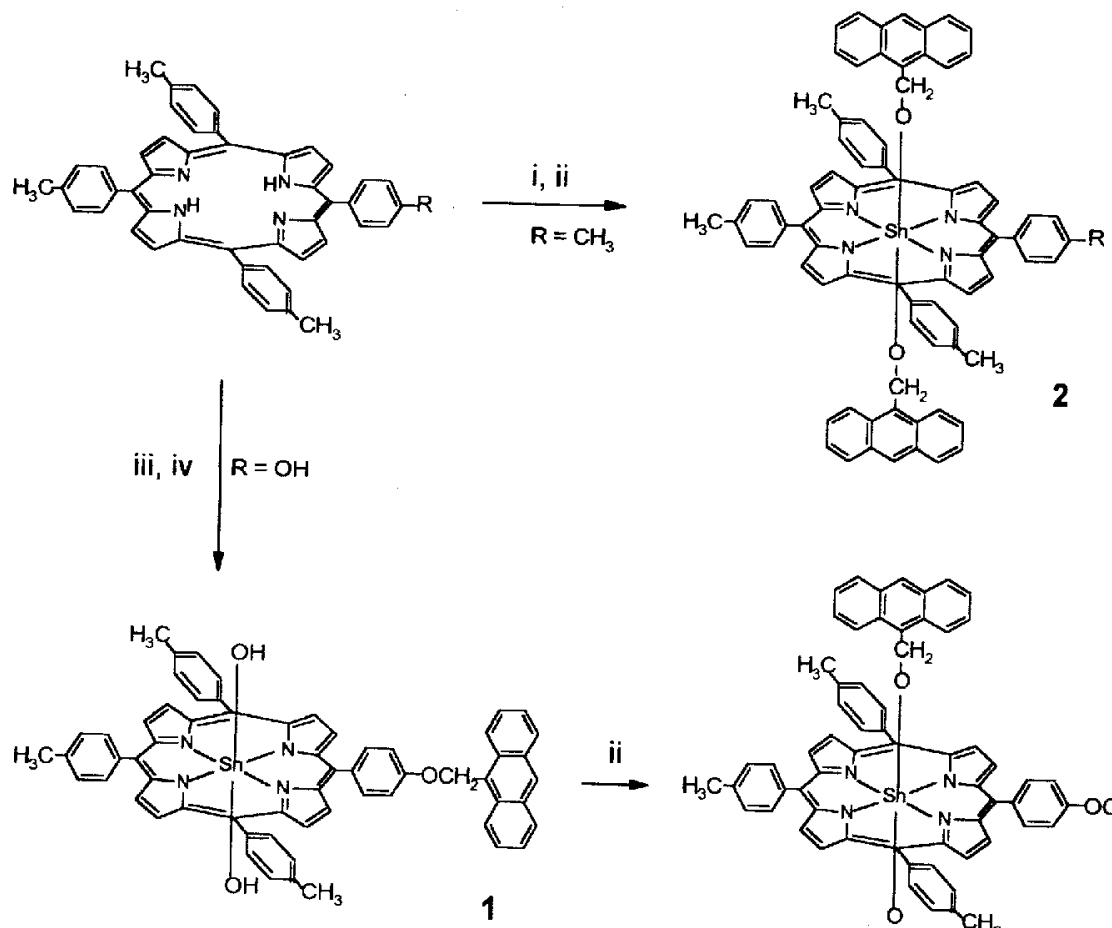

i) $\mathrm{SnCl}_{2}, \mathrm{Py}, \mathrm{NaOH}$

ii) $\mathrm{AnCH}_{2} \mathrm{OH}, \mathrm{C}_{6} \mathrm{H}_{6}$

iii) $\mathrm{K}_{2} \mathrm{CO}_{3} / \mathrm{DMF}, \mathrm{AnCH} \mathrm{H}_{2} \mathrm{OH}$

iv) $\mathrm{SnCl}_{2}, \mathrm{Py}, \mathrm{NH}_{3}$

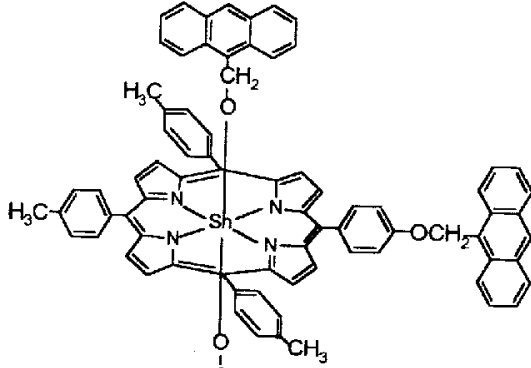

$\mathrm{CH}_{2}$

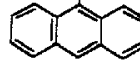

3

Figure 1. Molecular structures of the 'Sn(IV) porphyrin-anthracene' D-A systems investigated in the present study.

\section{Experimental}

\subsection{Synthesis}

The chemicals and solvents utilized in this study were purchased from either Aldrich Chemical Co. (USA) or E Merck (India). 5,10,15,20-Tetra(p-tolyl)porphyrin $\left(\mathrm{H}_{2} \mathrm{~L}^{1}\right){ }^{12}$ 5,10,15,20-tetra( $p$-tolyl)porphyrinato $\operatorname{tin}(\mathrm{IV})$ dihydroxide $\left(\left[\left(\mathrm{L}^{1}\right) \mathrm{Sn}^{\mathrm{IV}}(\mathrm{OH})_{2}\right]\right){ }^{13}$ 5-(4hydroxyphenyl) $10,15,20$-tri $\left(p\right.$-tolyl) porphyrin $\left(\mathrm{H}_{2} \mathrm{~L}^{2}\right),{ }^{14} \quad 5,10,15,20$-tetraphenylporphyrinato zinc(II) ([(TPP) $\left.\left.\mathrm{Zn}^{\mathrm{II}}\right]\right)^{12}$ and 5-(4-(9-methyloxyanthracenyl)phenyl)-10,15, 20 -tri( $p$-tolyl) porphyrin ${ }^{15}$ were synthesized according to reported procedures.

2.1a 5-(4-(9-Methyloxyanthracenyl)phenyl)-10,15,20-tri(p-tolyl)porphyrinato $\quad \operatorname{tin}(I V) \quad d i-$ hydroxide (1): A $0.1 \mathrm{~g}(0.12 \mathrm{mmol})$ sample of 5-(4-(9-methyloxyanthracenyl)phenyl)10,15,20-tri(p-tolyl) porphyrin and $0.1 \mathrm{~g}(0.53 \mathrm{mmol})$ of $\mathrm{SnCl}_{2}$ were dissolved in $25 \mathrm{ml}$ of pyridine. The reaction mixture was refluxed for $2 \mathrm{~h}$. To this, $5 \mathrm{ml}$ of aq. ammonia $(25 \%$ $v / v$ ) was added and the resulting mixture stirred for $1 \mathrm{~h}$. at $50^{\circ} \mathrm{C}$. The solvent was evaporated to dryness under reduced pressure. The residue was dissolved in $\approx 50 \mathrm{ml}$ of $\mathrm{CHCl}_{3}$, then washed repeatedly with water. The $\mathrm{CHCl}_{3}$ layer was dried over anhydrous $\mathrm{Na}_{2} \mathrm{SO}_{4}$ after which it was evaporated to $\approx 5 \mathrm{ml}$. This solution was applied onto an alumina 
(neutral, activity 1) column. The desired product was eluted using $\mathrm{CHCl}_{3}-\mathrm{CH}_{3} \mathrm{OH}(97: 3$, $v / v)$ mixture. Solvent was evaporated and the product was recrystallized in $\mathrm{CH}_{2} \mathrm{Cl}_{2}-$ hexane mixture. Yield: 80\%. Anal: Calcd. for: $\mathrm{C}_{62} \mathrm{H}_{46} \mathrm{~N}_{4} \mathrm{O}_{3} \mathrm{Sn}$ : C, 73.46; H, 4.57; N, 5.53\%; Found: $\mathrm{C}, 74.51 ; \mathrm{H}, 4.83$; N, 5.55\%; ${ }^{13} \mathrm{C}$ NMR (CDCl, $\mathrm{TMS}$ ): $\&$ ppm: 147.0, $146 \cdot 9$, 138.6, 138.0, 136.5, 135.2, 132.7, 131.7, 131.4, 129.3, 127.8, 126.9, 125.3, 124.2, $121 \cdot 4,113 \cdot 6,63 \cdot 3,21 \cdot 6$.

2.1b 5,10,15,20-Tetra(p-tolyl)porphyrinato trans-bis(methyloxyanthracenato) tin(IV) (2): A mixture containing $\left[\left(\mathrm{L}^{1}\right) \mathrm{Sn}^{\mathrm{IV}}(\mathrm{OH})_{2}\right] \quad(0.05 \mathrm{~g}, \quad 0.06 \mathrm{mmol})$ and 9-methanol anthracene $\left(\mathrm{AnCH}_{2} \mathrm{OH}\right)(0.06 \mathrm{~g}, 0.29 \mathrm{mmol})$ was dissolved in $20 \mathrm{ml}$ of dry benzene. The solution was refluxed under the nitrogen atmosphere for $12 \mathrm{~h}$. The solvent was evaporated and the residue was dissolved in minimum amount of $\mathrm{CHCl}_{3}$ and applied onto an alumina (neutral, activity 1) column. Elution with $\mathrm{CHCl}_{3}$ removed a light yellow coloured fraction, which was discarded. The next purple coloured fraction was collected by eluting with $\mathrm{CHCl}_{3}-\mathrm{CH}_{3} \mathrm{OH}(98: 2, v / v)$ and the solvent was evaporated to get the desired product. Yield: $74 \%$. Anal: Calcd. for: $\mathrm{C}_{78} \mathrm{H}_{58} \mathrm{~N}_{4} \mathrm{O}_{2} \mathrm{Sn}$ : C, 77.93; H, 4.86; N,

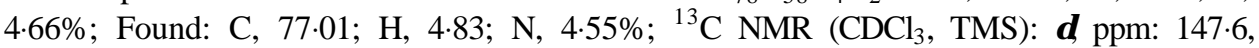
$147 \cdot 3$, 137.9, 135.1, 132.5, 131.6, 131.2, 130.3, 129.1, 128.3, 127.6, 126.3, 125.0, 123.9, $123 \cdot 3,57 \cdot 2,21 \cdot 5$.

2.1c 5-(4-(9-Methyloxyanthracenyl)phenyl)-10,15,20-tri(p-tolyl)porphyrinato

transbis(methyloxyanthracenato) tin(IV) (3): Compound $\mathbf{1}(0.05 \mathrm{~g}, 0.05 \mathrm{mmol})$ and $\mathrm{AnCH}_{2} \mathrm{OH}$ $(0.05 \mathrm{~g}, 0.24 \mathrm{mmol})$ were dissolved in $20 \mathrm{ml}$ of dry benzene. The resulting mixture was refluxed under nitrogen atmosphere for $12 \mathrm{~h}$. The solvent was evaporated and the residue was dissolved in minimum amount of $\mathrm{CHCl}_{3}$ and applied onto an alumina (neutral, activity 1) column. Elution with $\mathrm{CHCl}_{3}$ removed a light yellow coloured fraction, which was discarded. The purple coloured second fraction was collected by eluting with $\mathrm{CHCl}_{3}-\mathrm{CH}_{3} \mathrm{OH}(98: 2, v / v)$ and solvent was evaporated to get the desired product. Yield: 70\%. Anal: Calcd. for: $\mathrm{C}_{92} \mathrm{H}_{66} \mathrm{~N}_{4} \mathrm{O}_{3} \mathrm{Sn}$ : C, 79.25; H, 4.77; N, 4.02\%; Found: C, 79.11; H, $4.62 ; \mathrm{N}, 4.55 \% ;{ }^{13} \mathrm{C} \mathrm{NMR}\left(\mathrm{CDCl}_{3}\right.$, TMS): $\delta$ ppm: 147.6, 147.3, 138.6, 138.0, 135.1, $132 \cdot 6,131 \cdot 6,131 \cdot 2,130 \cdot 5,130 \cdot 3,129 \cdot 1,128 \cdot 2,127 \cdot 7,126 \cdot 8,126 \cdot 3,125 \cdot 0,124 \cdot 2,124 \cdot 0$, $123 \cdot 8,123 \cdot 7,123 \cdot 3,113 \cdot 6,63 \cdot 4,57 \cdot 2,21 \cdot 5$.

\subsection{Methods}

Solvents used for spectroscopic and electrochemical experiments were further purified using standard procedures. ${ }^{16}$ Each investigated porphyrin was purified on a short alumina column before being subjected to physical measurements. Care was taken to avoid the entry of direct, ambient light into the samples in all spectroscopic and electrochemical experiments. Unless otherwise specified, all experiments were carried out at $293 \pm 3 \mathrm{~K}$.

FAB-mass spectra were recorded with a JEOL SX 102/DA-6000 mass spectrometer/ data system. Elemental analysis was carried out with the Perkin-Elmer Model 240-C CHN analyser. UV-Vis spectra were recorded with a Shimadzu Model UV-3101-PC UV-Vis spectrophotometer. Concentration of the samples used for these measurements ranged from $\sim 2 \times 10^{-6} \mathrm{M}$ (Soret bands and anthracene bands) to $\sim 5 \times 10^{-5} \mathrm{M}$ (Q-bands). ${ }^{1} \mathrm{HNMR}$ (200 MHz; $1 \mathrm{D}$ and $\left.{ }^{1} \mathrm{H}-{ }^{1} \mathrm{H} \mathrm{COSY}\right)$ and ${ }^{13} \mathrm{C} \mathrm{NMR}(50 \mathrm{MHz})$ spectra were recorded with a Bruker NR-200 spectrometer using $\mathrm{CDCl}_{3}$ as the solvent and tetramethylsilane (TMS) as an internal standard. 
Steady-state fluorescence spectra were recorded using a Jasco Model FP-777 spectrofluorimeter. The emitted quanta were detected at right angles to the incident beam. The utilized concentrations of the fluorophores were such that the optical densities (OD) at the excitation wavelengths were always less than $0 \cdot 2$. The fluorescence quantum yields $(\phi)$ were estimated by integrating the areas under the fluorescence curves and by using either $\left[(\mathrm{TPP}) \mathrm{Zn}^{\mathrm{II}}\right] \quad\left(\phi=0.036\right.$ in $\mathrm{CH}_{2} \mathrm{Cl}_{2}$ for excitation into the porphyrin band, $420 / 525 \mathrm{~nm})$ or anthracene ( $\mathrm{An})\left(\phi=0.27\right.$ in $\mathrm{CH}_{2} \mathrm{Cl}_{2}$ for excitation into the anthracene band, $250 \mathrm{~nm}$ ) as the standards. ${ }^{17,18}$ Refractive index corrections have been incorporated while reporting the fluorescence data in various solvents. ${ }^{19}$ Dilute solutions $\left(\sim 10^{-7} \mathrm{M}\right)$ of the fluorophores were used for excitation spectral measurements. Corrections to the instrument response function and procedures for the spectral normalization that were employed during the estimations of excitation energy transfer efficiencies are essentially similar to those described in our previous studies. ${ }^{11,20-24}$

Cyclic voltammetric experiments $\left(\mathrm{CH}_{2} \mathrm{Cl}_{2}\right.$ and $0 \cdot 1 \mathrm{M}$ tetrabutylammonium perchlorate, TBAP) were performed on a Princeton Applied Research (PAR) 174A polarographic analyser coupled with a PAR 175 universal programmer and a PAR RE $0074 \mathrm{x}-\mathrm{y}$ recorder, as detailed in our previous studies ${ }^{20-25} \mathrm{Fc}^{+} / \mathrm{Fc}$ couple $(\mathrm{Fc}=$ ferrocene $)$ was used to calibrate redox potential values.

PM3 calculations were performed using MOPAC 93 on a Pentium III PC.

\section{Results and discussion}

\subsection{Ground state properties}

Synthesis of the three new D-A compounds has been accomplished as detailed in $\S 2$. Satisfactory elemental (CHN) analyses were obtained for compounds 1-3 but the mass spectrum of each of these axial-bonding type tin(IV) porphyrins showed only a low intensity peak due to the parent $M^{+}$ion. Nevertheless, peaks due to the fragments obtained upon elimination of the axial ligands were found to be intense. Weak signals (1-15\%) for $M^{+}$fragments of the axial-bonding type, penta- and hexa-coordinated tin(IV) porphyrins have been noticed earlier by several workers including us. ${ }^{21,26-28}$

UV-Vis spectra of the three covalently linked D-A compounds are illustrated in figure 2. The wavelength of maximum absorbance $\left(\lambda_{\max }, \mathrm{nm}\right)$ and molar extinction coefficient $(\log \varepsilon)$ values of 1-3 and those of their constituent individual components (i.e. $\left[\left(\mathrm{L}^{1}\right) \mathrm{Sn}^{\mathrm{IV}}(\mathrm{OH})_{2}\right]$ and $\left.\mathrm{An}\right)$ are summarized in table 1. From comparison of these data, it is clear that the anthracene part of the diad, triad and tetrad molecules strongly absorbs between 200 and $300 \mathrm{~nm}$, a region in which the porphyrin part of the molecule shows minimum absorbance. Analogously, the porphyrin part of each compound shows an intense Soret band and two less intense Q-bands in the region $(400-650 \mathrm{~nm})$ where the anthracene chromophore shows minimum absorbance. Data given in table 1 suggest that the $\lambda_{\max }$ values of these bands are within the same range as those of $\left[\left(\mathrm{L}^{1}\right) \mathrm{Sn}^{\mathrm{IV}}(\mathrm{OH})_{2}\right]$. The absorption bands due to the anthracene component/s $(256 \pm 1 \mathrm{~nm})$ of these D-A compounds are red-shifted by $6 \mathrm{~nm}$ in comparison with the corresponding band of anthracene itself $(251 \mathrm{~nm}) .{ }^{29}$ While $\log \varepsilon$ values of the bands due to the porphyrin part are slightly reduced in comparison with the corresponding values of unlinked $\left[\left(\mathrm{L}^{1}\right) \mathrm{Sn}^{\mathrm{IV}}(\mathrm{OH})_{2}\right]$, those of the anthracene part vary in the order $\mathbf{1}<\mathbf{2}<\mathbf{3}$, as expected. Finally, $\lambda_{\max }$ and $\log \boldsymbol{\varepsilon}$ values as well as the spectral shapes of the bands of these covalently linked diad, triad and tetrad compounds are found to be similar to those of solutions containing one 


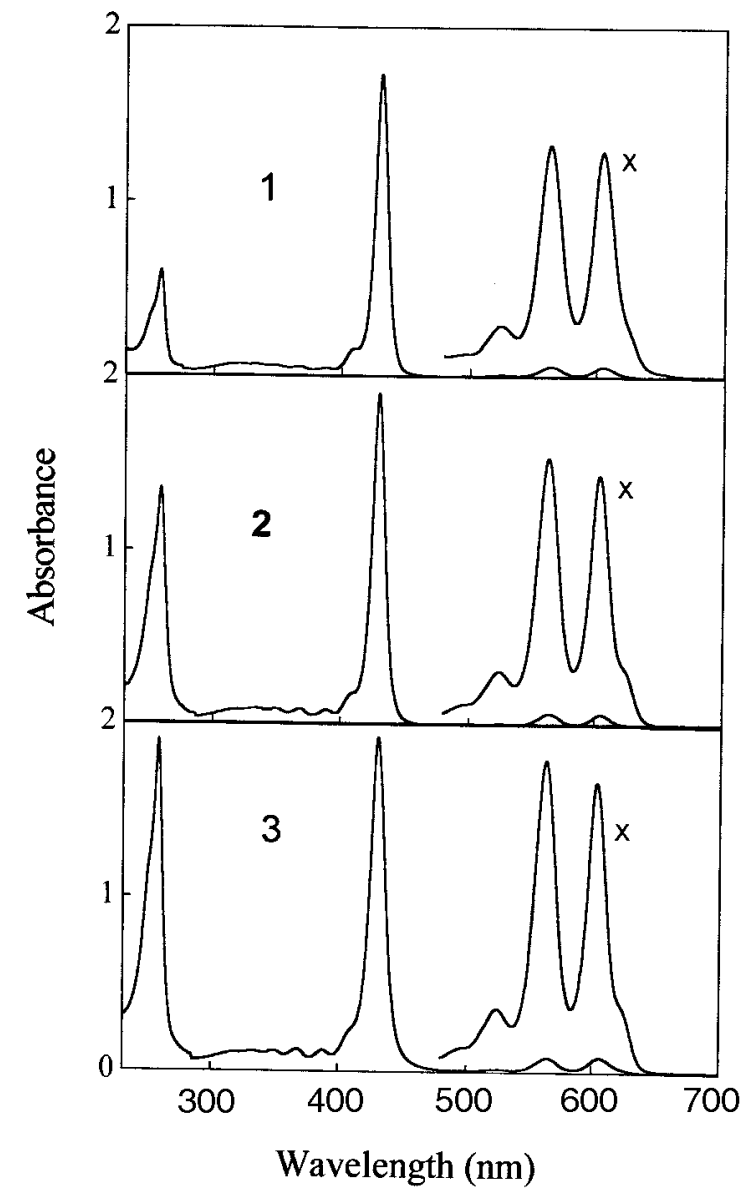

Figure 2. UV-Vis spectra of $\mathbf{1}, \mathbf{2}$ and $\mathbf{3}$ in $\mathrm{CH}_{2} \mathrm{Cl}_{2}$.

mole equivalent of porphyrin and one, two or three mole equivalents of anthracene respectively. These results suggest that there exists, if any, only marginal ground-state $\pi$ $\pi$ interaction between the donor and acceptor components of these new type of D-A systems.

The ${ }^{1} \mathrm{H}$ NMR spectral data $\left(\mathrm{CDCl}_{3}\right.$, TMS) of compounds $\mathbf{1}, \mathbf{2}$ and $\mathbf{3}$ and that of their individual constituents (viz: $\left[\left(\mathrm{L}^{1}\right) \mathrm{Sn}^{\mathrm{IV}}(\mathrm{OH})_{2}\right]$ and $\left.\mathrm{AnCH}_{2} \mathrm{OH}\right)$ are summarized in table 2 . The spectra are highly characteristic and the resonance positions as well as the corresponding intensities of the signals arising from various protons in compounds 1-3 are in conformity with the proposed structures (see figure 1). While the aromatic protons of the anthracene subunit (peripheral) of 1 resonate between 8.60 and $7.66 \mathrm{ppm}$, the corresponding protons of $\mathbf{2}$ (axial) and $\mathbf{3}$ (axial and peripheral) are shielded and appear between 8.14 and $7.57 \mathrm{ppm}$. Similarly, the peripheral $-\mathrm{OCH}_{2}$ protons of diad 1 resonate as a singlet at $6.33 \mathrm{ppm}$, the axial $-\mathrm{OCH}_{2}$ protons of triad 2 are shielded and 
Table 1. UV-Vis data in $\mathrm{CH}_{2} \mathrm{Cl}_{2}$.

\begin{tabular}{|c|c|c|c|c|c|}
\hline \multirow[b]{2}{*}{ Compound } & \multicolumn{4}{|c|}{$\begin{array}{l}\text { Porphyrin transitions } \\
\quad \lambda_{\max }, \mathrm{nm}(\log \varepsilon)\end{array}$} & \multirow{2}{*}{$\begin{array}{c}\text { Anthracene } \\
\text { transition } \\
\lambda_{\max }, \mathrm{nm}(\log \varepsilon)\end{array}$} \\
\hline & $Q-\mathrm{b}$ & ands & Soret & and & \\
\hline Anthracene & - & & & & $\begin{array}{c}251 \\
(5 \cdot 19)\end{array}$ \\
\hline$\left[\left(\mathrm{L}^{1}\right) \mathrm{Sn}^{\mathrm{IV}}(\mathrm{OH})_{2}\right]$ & $\begin{array}{c}603 \\
(4 \cdot 62)\end{array}$ & $\begin{array}{c}563 \\
(4 \cdot 63)\end{array}$ & $\begin{array}{c}524 \\
(3.56)\end{array}$ & $\begin{array}{c}428 \\
(5 \cdot 76)\end{array}$ & $\begin{array}{c}256 \\
(3.92)^{b}\end{array}$ \\
\hline 1 & $\begin{array}{c}606 \\
(4 \cdot 17)\end{array}$ & $\begin{array}{c}564 \\
(4 \cdot 16)\end{array}$ & $\begin{array}{l}525 \\
(3 \cdot 51)\end{array}$ & $\begin{array}{c}430 \\
(5 \cdot 25)\end{array}$ & $\begin{array}{c}257 \\
(4 \cdot 78)\end{array}$ \\
\hline 2 & $\begin{array}{c}605 \\
(4 \cdot 10)\end{array}$ & $\begin{array}{c}564 \\
(4 \cdot 10)\end{array}$ & $\begin{array}{c}524 \\
(3.46)\end{array}$ & $\begin{array}{c}427 \\
(5 \cdot 33)\end{array}$ & $\begin{array}{c}256 \\
(5 \cdot 04)\end{array}$ \\
\hline 3 & $\begin{array}{c}607 \\
(4 \cdot 15)\end{array}$ & $\begin{array}{c}565 \\
(4 \cdot 12)\end{array}$ & $\begin{array}{c}525 \\
(3 \cdot 50)\end{array}$ & $\begin{array}{c}429 \\
(5 \cdot 36)\end{array}$ & $\begin{array}{c}255 \\
(5 \cdot 19)\end{array}$ \\
\hline
\end{tabular}

${ }^{a}$ Error limits: $\lambda_{\max }, \pm 1 \mathrm{~nm}$; $\log \varepsilon, \pm 7 \%$; ${ }^{b}$ not a peak (given only for comparison)

Table 2. $\quad{ }^{1} \mathrm{H}$ NMR data in $\mathrm{CDCl}_{3}$ (TMS). All values in $\delta(\mathrm{ppm}) .{ }^{\mathrm{a}}$

\begin{tabular}{|c|c|c|c|c|c|c|c|c|c|}
\hline \multirow[b]{2}{*}{ Compd. } & \multicolumn{4}{|c|}{ Porphyrin protons } & \multicolumn{5}{|c|}{ Anthracene protons } \\
\hline & $\begin{array}{c}\beta- \\
\text { pyrrole }^{\mathrm{b}}\end{array}$ & $\begin{array}{c}o- \\
\text { phenyl }\end{array}$ & $\begin{array}{c}m- \\
\text { phenyl }\end{array}$ & $-\mathrm{CH}_{3}$ & Aromatic & & & $\begin{array}{l}\text { (Periphe- } \\
\text { ral) }-\mathrm{CH}_{2}\end{array}$ & $\begin{array}{c}\text { (Axial) } \\
-\mathrm{CH}_{2}\end{array}$ \\
\hline $\mathrm{AnCH}_{2} \mathrm{OH}$ & & & & & $\begin{array}{c}8.44 \\
(m, 1 \mathrm{H})\end{array}$ & $\begin{array}{c}8 \cdot 12 \\
(m, 4 \mathrm{H})\end{array}$ & $\begin{array}{c}7 \cdot 32 \\
(s, 4 \mathrm{H})\end{array}$ & $\begin{array}{c}5 \cdot 92 \\
(s, 2 \mathrm{H})\end{array}$ & - \\
\hline $\begin{array}{c}{\left[\left(\mathrm{L}^{1}\right) \mathrm{Sn}^{\mathrm{IV}}\right.} \\
\left.(\mathrm{OH})_{2}\right]\end{array}$ & $\begin{array}{c}9 \cdot 14 \\
(s, 8 \mathrm{H})\end{array}$ & $\begin{array}{c}8 \cdot 22 \\
(d, 8 \mathrm{H})\end{array}$ & $\begin{array}{c}7.62 \\
(d, 8 \mathrm{H})\end{array}$ & $\begin{array}{c}2 \cdot 74 \\
(s, 12 \mathrm{H})\end{array}$ & & & & & \\
\hline 1 & $\begin{array}{c}9 \cdot 18 \\
(m, 8 \mathrm{H})\end{array}$ & $\begin{array}{c}8 \cdot 24 \\
(m, 8 \mathrm{H})\end{array}$ & $\begin{array}{c}7 \cdot 64 \\
(m, 8 \mathrm{H})\end{array}$ & $\begin{array}{c}2.75 \\
(s, 9 \mathrm{H})\end{array}$ & $\begin{array}{c}8.60 \\
(m, 3 \mathrm{H})\end{array}$ & $\begin{array}{c}8 \cdot 26 \\
(m, 2 \mathrm{H})\end{array}$ & $\begin{array}{c}7 \cdot 66 \\
(m, 4 \mathrm{H})\end{array}$ & $\begin{array}{c}6 \cdot 33 \\
(s, 2 \mathrm{H})\end{array}$ & \\
\hline 2 & $\begin{array}{c}9.15 \\
(s, 8 \mathrm{H})\end{array}$ & $\begin{array}{c}8.04 \\
(d, 8 \mathrm{H})\end{array}$ & $\begin{array}{c}7.55 \\
(m, 8 \mathrm{H})\end{array}$ & $\begin{array}{c}2 \cdot 74 \\
(s, 12 \mathrm{H})\end{array}$ & $\begin{array}{c}8.44 \\
(m, 8 \mathrm{H})\end{array}$ & $\begin{array}{c}8 \cdot 21 \\
(m, 2 \mathrm{H})\end{array}$ & $\begin{array}{c}7.57 \\
(s, 8 \mathrm{H})\end{array}$ & & $\begin{array}{c}5 \cdot 65 \\
(s, 4 \mathrm{H})\end{array}$ \\
\hline 3 & $\begin{array}{c}9 \cdot 16 \\
(m, 8 \mathrm{H})\end{array}$ & $\begin{array}{c}8 \cdot 14 \\
(m, 8 \mathrm{H})\end{array}$ & $\begin{array}{c}7 \cdot 58 \\
(m, 8 \mathrm{H})\end{array}$ & $\begin{array}{c}2.76 \\
(s, 9 \mathrm{H})\end{array}$ & $\begin{array}{c}8.41 \\
(m, 3 \mathrm{H})\end{array}$ & $\begin{array}{c}8 \cdot 14 \\
(m, 12 \mathrm{H})\end{array}$ & $\begin{array}{c}7.58 \\
(m, 12 \mathrm{H})\end{array}$ & $\begin{array}{c}6 \cdot 32 \\
(s, 2 \mathrm{H})\end{array}$ & $\begin{array}{c}5.62 \\
(s, 4 \mathrm{H})\end{array}$ \\
\hline
\end{tabular}

a Error limits: $\delta, \pm 0 \cdot 1 \mathrm{ppm} ;{ }^{\text {b }}$ less intense 'side-bands' due to 4 -bond ${ }^{117,119}$ Sn-H couplings are also discernible at the wings of these $\beta$-pyrrole proton resonances ${ }^{30}$

resonate, again as a singlet, at $5.65 \mathrm{ppm}$. Tetrad $\mathbf{3}$ shows two separate singlets at 5.62 and $6.32 \mathrm{ppm}$ due to the axial and peripheral $-\mathrm{OCH}_{2}$ protons respectively. The case is similar with the proton-decoupled ${ }^{13} \mathrm{C}$ NMR spectra of these systems. While the spacer $-\mathrm{OCH}_{2}$ carbons of 1 (peripheral) and $\mathbf{2}$ (axial) resonate at 63.3 and $57.3 \mathrm{ppm}$ respectively, those of 3 are seen at 63.4 (peripheral) and 57.2 (axial) ppm (see §2). Shielding of the axial $-\mathrm{OCH}_{2}$ protons and also the carbons in $\mathbf{2}$ and $\mathbf{3}$ can be rationalized in terms of the ring current exerted by the basal porphyrin. ${ }^{31}$

The NMR results described above suggest that there is minimal $\pi \pi$ interaction between the porphyrin and anthracene subunits and this is unlike the case with a series of isomeric porphyrin-anthracene $(\mathrm{P}-\mathrm{A})$ diads and a supramolecular pentad system reported by us earlier. ${ }^{15,22}$ This is reasonable if one considers that the previously reported isomeric 
P-A diad and pentad systems, where the anthracene subunits are linked at the porphyrin peripheral positions, were constructed using the free-base porphyrin wherein a facile $\pi-\pi$ interaction between the porphyrin and the peripheral anthracene subunits is possible. In contrast, the hydroxy/anthracene subunits present at the axial sites of the tin(IV) porphyrins reported here can hinder the approach of the peripheral anthracene subunits over the porphyrin $\pi$-plane in $\mathbf{1}$ and $\mathbf{3}$. $\boldsymbol{\pi}-\boldsymbol{\pi}$ interaction between the basal porphyrin and axially ligated anthracene subunits has, however, been observed in $\left.\left[(\mathrm{P}) \operatorname{Sn}(\mathrm{OC}(\mathrm{O}) \mathrm{An})_{2}\right)\right]$ where $\mathrm{P}_{\text {is }} \mathrm{L}^{1}$ and $\mathrm{AnOC}(\mathrm{O})$ is the axially ligated anthracene 9-carboxylic acid subunit. ${ }^{32}$

Table 3 summarizes redox potential data $\left(\mathrm{CH}_{2} \mathrm{Cl}_{2}, 0 \cdot 1 \mathrm{M} \mathrm{TBAP}\right)$ of the D-A systems investigated in this study along with that of their constituent reference compounds $\left(\left[\left(\mathrm{L}^{1}\right) \mathrm{Sn}^{\mathrm{IV}}(\mathrm{OH})_{2}\right]\right.$ and $\left.\mathrm{AnCH}_{2} \mathrm{OH}\right)$. Each investigated new compound shows up to two reduction peaks and up to two oxidation peaks under the experimental conditions employed in this study. Wave analysis suggested that while the reduction processes represent reversible $\left(i_{\mathrm{pc}} / i_{\mathrm{pa}}=0 \cdot 9-1 \cdot 0\right)$ and diffusion-controlled $\left(i_{\mathrm{pc}} / v^{1 / 2}=\right.$ constant in the scan rate $(v)$ rage $50-500 \mathrm{mV} / \mathrm{s})$ one-electron transfer $\left(\Delta E_{P}=60-70 \mathrm{mV} ; \Delta E_{P}=65 \pm\right.$ $3 \mathrm{mV}$ for ferrocene ${ }^{+} /$ferrocene couple) reactions, the corresponding oxidation processes are all irreversible under similar experimental conditions. ${ }^{33}$ The first one-electron oxidations of the porphyrin part of $\mathbf{1}, \mathbf{2}$ and $\mathbf{3}$ are assigned to the peaks appearing at 1.30, 1.33 and $1.38 \mathrm{~V}$ respectively and the corresponding reduction potentials to those at -0.94 , -0.99 and $-0.92 \mathrm{~V}$ respectively. ${ }^{34}$ The second one-electron reduction of the porphyrin part occurs at potentials more negative than $-1.3 \mathrm{~V}$ in each case. The bound anthracene subunit (peripheral and axial) was found to be oxidized between 1.48 and $1.60 \mathrm{~V}$ and its reduction was not observed within the solvent limit under experimental conditions $(\sim-1.8 \mathrm{~V})$.

Overall, UV-Vis, NMR and redox potential data of the diad, triad and tetrad systems investigated here not only provide evidence for their structural integrity but also suggest that there exists minimal interaction between the porphyrin and the anthracene (axial/peripheral) $\pi$-planes. Both porphyrin and anthracene subunits of these systems retain their individual characteristics in the ground state.

\subsection{Singlet state properties}

Steady state fluorescence spectra of $\mathbf{1 , 2}$ and $\mathbf{3}$ were measured in four solvents: hexane, $\mathrm{CH}_{2} \mathrm{Cl}_{2}, \mathrm{CH}_{3} \mathrm{OH}$ and $\mathrm{CH}_{3} \mathrm{CN}$. The relevant data are summarized in table 4. Spectra obtained for these D-A systems, when they are irradiated at the porphyrin absorption band $\left(\lambda_{\mathrm{exc}}=420 / 525 \mathrm{~nm}\right)$, are seen to be similar to the spectrum of $\left[\left(\mathrm{L}^{1}\right) \mathrm{Sn}^{\mathrm{IV}}(\mathrm{OH})_{2}\right]$ (e.g.

Table 3. Redox potential data in $\mathrm{CH}_{2} \mathrm{Cl}_{2}, 0 \cdot 1 \mathrm{M}$ TBAP.

\begin{tabular}{lcccc}
\hline & \multicolumn{4}{c}{ Potential $V$ vs SCE $^{\mathrm{a}}$} \\
\cline { 2 - 5 } Compound & $P \rightarrow P^{+}$ & $\mathrm{An} \rightarrow \mathrm{An}^{+}$ & $P \rightarrow P^{-}$ & $P^{-} \rightarrow P^{2-}$ \\
\hline $\mathrm{AnCH}_{2} \mathrm{OH}$ & - & 1.44 & - & - \\
{$\left[\left(\mathrm{L}^{1}\right) \mathrm{Sn}^{\mathrm{IV}}(\mathrm{OH})_{2}\right]$} & $1.39^{\mathrm{b}}$ & - & -0.88 & -1.02 \\
$\mathbf{1}$ & $1.30^{\mathrm{b}}$ & $1.48^{\mathrm{b}}$ & -0.94 & -1.32 \\
$\mathbf{2}$ & $1.33^{\mathrm{b}}$ & $1.55^{\mathrm{b}}$ & -0.99 & -1.38 \\
$\mathbf{3}$ & $1.38^{\mathrm{b}}$ & $1.60^{\mathrm{b}}$ & -0.92 & -1.32 \\
\hline
\end{tabular}

${ }^{\mathrm{a}}$ Error limits: $E_{1 / 2}, \pm 0.03 \mathrm{~V}$; ${ }^{\mathrm{b}}$ quasi-reversible/irreversible 


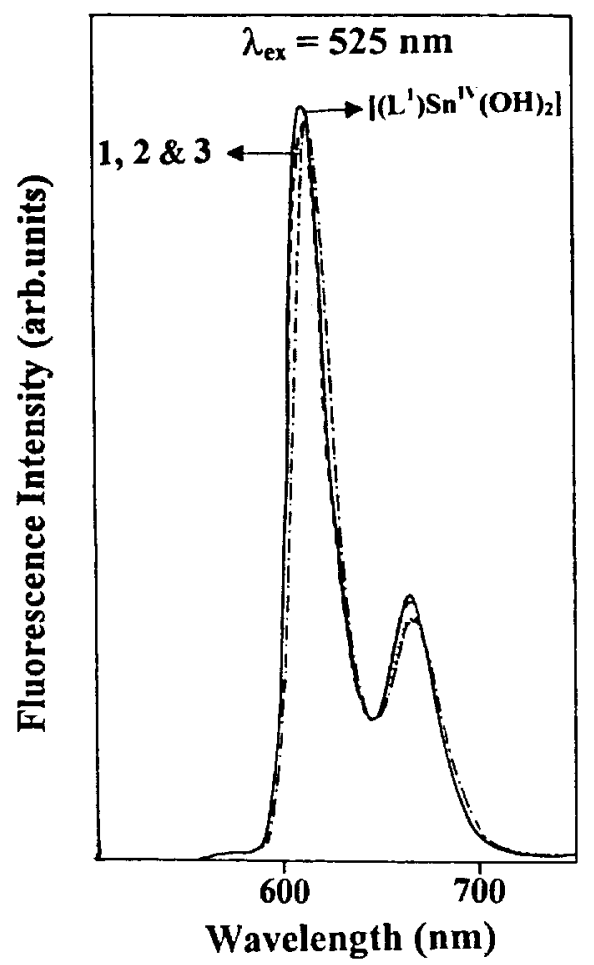

Figure 3. Fluorescence spectra of equiabsorbing solutions $(\mathrm{OD}=0 \cdot 18)$ of $\left[\left(\mathrm{L}^{1}\right) \mathrm{Sn}^{\mathrm{IV}}(\mathrm{OH})_{2}\right], \mathbf{1}, 2$ and 3 in $\mathrm{CH}_{2} \mathrm{Cl}_{2}\left(\lambda_{\text {ex }}=525 \mathrm{~nm}\right)$.

figure 3). However, excitation at $250 \mathrm{~nm}$ (anthracene absorption) resulted in fluorescence bands that are red-shifted in comparison with the bands due to free anthracene. The red shifts observed here can be a consequence of substitution at the 9-position of anthracene ${ }^{29}$ as illustrated in figure 4, which compares the spectra of 1-3 with the spectrum of $\mathrm{AnCH}_{2} \mathrm{OH}$ (9-substituted anthracene derivative) in $\mathrm{CH}_{2} \mathrm{Cl}_{2}$. From an overlay of the absorption and fluorescence spectra of these D-A systems, the $0-0$ spectroscopic transition energies $\left(E_{0-0}\right)$ of the anthracene moiety $(3.23 \pm 0.05 \mathrm{eV})$ and the porphyrin moiety $(2.04 \pm 0.05 \mathrm{eV})$ were obtained, and these values are similar to those of anthracene ${ }^{18}$ and $\left[\left(\mathrm{L}^{1}\right) \mathrm{Sn}^{\mathrm{IV}}(\mathrm{OH})_{2}\right],{ }^{21}$ respectively.

Whereas the fluorescence quantum yield $(\phi)$ for excitation into the porphyrin part of each D-A compound was similar to that of $\left[\left(\mathrm{L}^{1}\right) \mathrm{Sn}^{\mathrm{IV}}(\mathrm{OH})_{2}\right]$ (figure 3), fluorescence from the anthracene part was found to be quenched, in comparison with the fluorescence of free anthracene chromophore $\left(\mathrm{AnCH}_{2} \mathrm{OH}\right)$, only for $\mathbf{1}$ and $\mathbf{3}$ in $\mathrm{CH}_{2} \mathrm{Cl}_{2}$ (figure 4). Measurements carried out with $\mathbf{2}$ under similar experimental conditions of solvent and excitation wavelength suggested that the fluorescence quantum yield for this compound is quite similar to that of anthracene itself. As seen in figure 4, fluorescence quenching of the appended anthracene follows the order $\mathbf{1}>\mathbf{3}>\mathbf{2}$.

The evaluated quenching efficiency $(Q)$,

$$
Q=\frac{\phi\left(\mathrm{AnCH}_{2} \mathrm{OH}\right)-\phi(\mathbf{1}-\mathbf{3})}{\phi\left(\mathrm{AnCH}_{2} \mathrm{OH}\right)},
$$




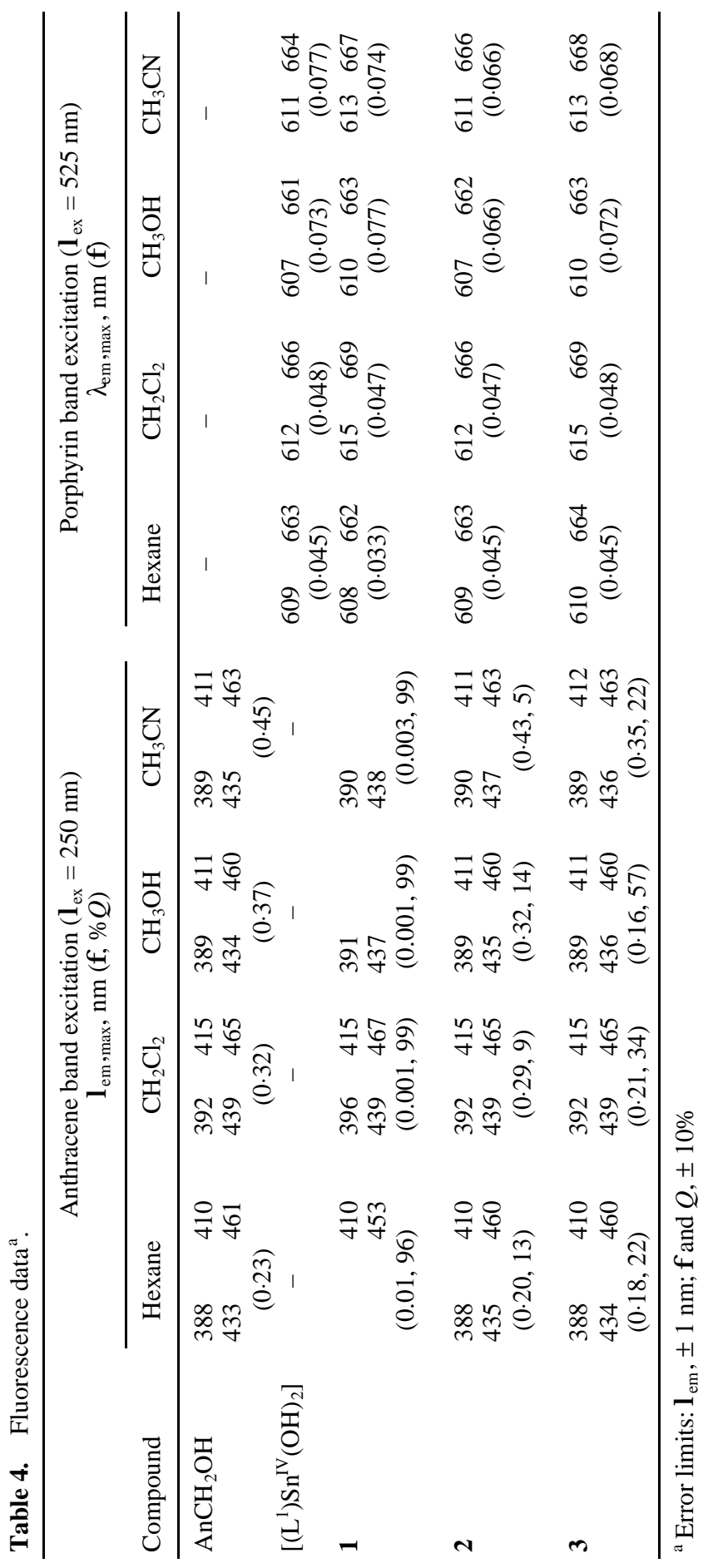




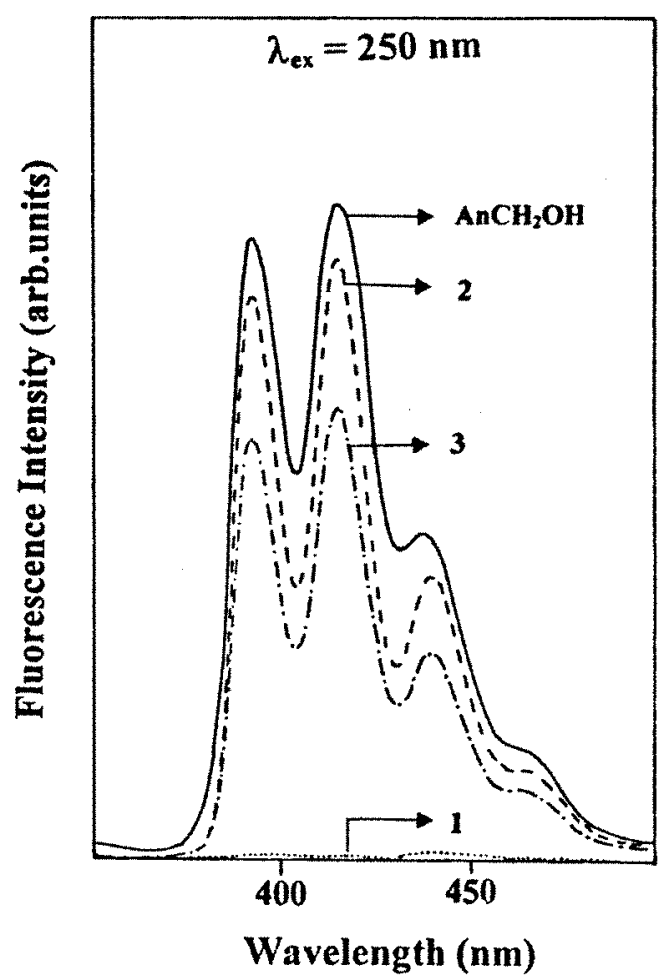

Figure 4. Fluorescence spectra of equiabsorbing solutions $(\mathrm{OD}=0 \cdot 14)$ of $\mathrm{AnCH}_{2} \mathrm{OH}, \mathbf{1}, 2$ and 3 in $\mathrm{CH}_{2} \mathrm{Cl}_{2}\left(\lambda_{\max }=250 \mathrm{~nm}\right)$.

where $\phi\left(\mathrm{AnCH}_{2} \mathrm{OH}\right)$ and $\phi(\mathbf{1 - 3})$ refer to the fluorescence quantum yields for $\mathrm{AnCH}_{2} \mathrm{OH}$ and the D-A systems respectively; $\lambda_{\mathrm{ex}}=250 \mathrm{~nm}$ ) and

$$
k_{\mathrm{obs}}=\frac{Q /(1-Q)}{\tau},
$$

where $\tau[=5 \cdot 2 \mathrm{~ns}]$ is the lifetime in $\mathrm{CH}_{2} \mathrm{Cl}_{2}{ }^{18}$ Values of $k_{\mathrm{obs}}$ have been calculated for these systems in $\mathrm{CH}_{2} \mathrm{Cl}_{2}$. These values vary as (error limits: $\pm 10 \%$ ),

$$
\begin{array}{ll}
Q: & \mathbf{2}(9)<\mathbf{3}(34)<\mathbf{1}(99), \\
k_{\text {obs }}: & \mathbf{2}\left(0.02 \times 10^{9} \mathrm{~s}^{-1}\right)<\mathbf{3}\left(0.09 \times 10^{9} \mathrm{~s}^{-1}\right)<\mathbf{1}\left(19 \times 0^{9} \mathrm{~s}^{-1}\right) .
\end{array}
$$

It should be noted here that the $k_{\text {obs }}$ values evaluated here are only operational numbers and do not necessarily reflect the actual rates of the quenching process. This is so because we have used the readily-available $\tau$ of free anthracene in these calculations and anthracene is not an ideal free donor in this situation. It should also be noted that the quenching of anthracene subunits reported here is not due to the competitive absorption of incident light by the porphyrin part of these D-A systems. This is because, at $250 \mathrm{~nm}$ the contribution of porphyrin absorption is insignificant $(<3-5 \%)$, compared to absorption due to the anthracene moiety in each compound (compare the $\log \boldsymbol{\varepsilon}$ values for $\mathbf{1 - 3}$ and $\left[\left(\mathrm{L}^{1}\right) \mathrm{Sn}^{\mathrm{IV}}(\mathrm{OH})_{2}\right]$ in the anthracene absorption region, table 1$)$. 
The observation that there exists a considerable overlap between the emission of anthracene and the absorption of porphyrin in these D-A systems (compare the corresponding spectra in figures 4 and 2) suggests that quenching of the anthracene fluorescence observed for $\mathbf{1}$ and $\mathbf{3}$ may be due to intramolecular excitation energy transfer from the singlet anthracene to the porphyrin. Indeed, excitation of $\approx 10^{-7} \mathrm{M}$ solution of these two D-A systems at $250 \mathrm{~nm}$ resulted in an appearance of well-defined porphyrin emission bands in $\mathrm{CH}_{2} \mathrm{Cl}_{2}$. This was not the case for 2 . Conclusive evidence for intramolecular EET comes from the excitation spectral measurements. When emission was recorded at the porphyrin emission maximum $(650 \mathrm{~nm})$, the excitation spectra of these D-A systems showed bands characteristic of anthracene absorption. The corrected and normalised excitation spectra of the diad, triad and tetrad compounds were overlayed with the corresponding absorption spectra in $\mathrm{CH}_{2} \mathrm{Cl}_{2}$. A comparison of the excitation and the absorption spectra in the $45.5 \times 10^{3}-37.0 \times 10^{3} \mathrm{~cm}^{-1}(220-270 \mathrm{~nm})$ region gave the energy transfer efficiencies $(\% T)$ for these $\mathrm{D}-\mathrm{A}$ compounds from which the rates of energy transfer $\left(k_{\mathrm{EN}}\right)$ have been calculated (3).

$$
k_{\mathrm{EN}}=\frac{T /(1-T)}{\tau} .
$$

The $\% T$ and $k_{\mathrm{EN}}$ values, in $\mathrm{CH}_{2} \mathrm{Cl}_{2}$, vary as:

$$
\begin{aligned}
& \% T: \quad 2(5)<\mathbf{3}(25)<\mathbf{1}(99), \\
& k_{\mathrm{EN}}: \mathbf{2}\left(0.01 \times 10^{9} \mathrm{~s}^{-1}\right)<\mathbf{3}\left(0.06 \times 10^{9} \mathrm{~s}^{-1}\right)<\mathbf{1}\left(19 \times 10^{9} \mathrm{~s}^{-1}\right) . \\
& \text { (error limits: } \left.\% T, k_{\mathrm{EN}} \pm 12 \%\right) .
\end{aligned}
$$

It is interesting that, by and large, $\% T$ (and $k_{\mathrm{EN}}$ ) values correlate well with the $Q$ (and $k_{\text {obs }}$ ) values for these D-A compounds suggesting that the quenching is entirely due to the EET from anthracene to the porphyrin. $Q$ values in the remaining three solvents (hexane, $\mathrm{CH}_{3} \mathrm{CN}$ and $\mathrm{CH}_{3} \mathrm{OH}$ ) are also similar in magnitude to that obtained in $\mathrm{CH}_{2} \mathrm{Cl}_{2}$. Therefore, it can be expected that EET is the major quenching pathway in these solvents as well, although a photoinduced electron transfer from anthracene to porphyrin cannot be neglected altogether, at least, in polar solvents. Indeed, PET reaction from anthracene to freebase porphyrin in polar environments has been well-documented in the literature. ${ }^{15,22-24}$ In addition, quenching of pyrene fluorescence in a recently reported phosphorus(V) porphyrin-pyrene system that is structurally analogous to compound $\mathbf{2}$ has been interpreted in terms of a PET (singlet pyrene $\rightarrow$ porphyrin) based mechanism operative in polar solvents. ${ }^{35}$ An EET-based mechanism was found to be operative only in less polar solvents like toulene for this system.

\subsection{Orientation dependence of EET}

An important observation that can be made from the singlet state activities of $\mathbf{1 - 3}$ is concerned with the orientation dependence of the EET reactions. To our knowledge, orientation dependence of EET in a porphyrin-based D-A system wherein the energy donors are simultaneously connected to a porphyrin at two distinctly different positions has never been reported. ${ }^{1-10}$ This has been clearly demonstrated in this study. The observations that $\% Q$ varies as $\mathbf{2}(9)<\mathbf{3}(34)<\mathbf{1}(99)$ and $\% T$ varies as $\mathbf{2}(5)<\mathbf{3}(25)<\mathbf{1}(99)$ suggest that EET is unidirectional in these systems. That is, there is a near lack of quenching in $\mathbf{2}$ (where the two anthracene subunits are connected only at the axial positions), a near $100 \%$ quenching in $\mathbf{1}$ (where the anthracene subunit is connected only 
at the peripheral site) and $\approx 30 \%$ quenching in $\mathbf{3}$ (where two anthracene subunits are connected at the axial- and the other one at the peripheral positions). Thus, the energy transfer is clearly favoured from the peripheral anthracene to the porphyrin in these new type of D-A systems. Note here that the peripheral anthracene subunit of $\mathbf{3}$ absorbs only $\sim 30 \%$ of the incident light at the excitation wavelength and a near $30 \%$ quenching observed for this system amounts, actually, to a $100 \%$ EET from the peripheral anthracene to the porphyrin.

What is the origin of unidirectional EET observed here? EET reactions can operate either by a dipole-dipole (Coulombic) mechanism involving the mutual interaction of electrons (Forster's mechanism) ${ }^{36}$ or by an exchange mechanism involving mutual exchange of electrons (Dexter's mechanism). ${ }^{37}$ While there is an explicit treatment of the orientation dependence of EET in the Forster's theory, Dexter's theory seems to implicitly treat this aspect as described below.

Forster mechanism predicts the rate constant $k_{\text {Forster }}$ for the EET to follow (4).

$$
k_{\text {Forster }}=\frac{8.8 \times 10^{-25} \kappa^{2} \phi_{D} J_{\text {Forster }}}{n^{4} \tau_{D} R^{6}} .
$$

Here, $n$ is the solvent refractive index, $\phi_{\mathrm{D}}$ and $\tau_{\mathrm{D}}$ are the fluorescence quantum yield and lifetime of the isolated donor, $\mathrm{K}^{2}$ is an orientation factor given by

$$
\kappa^{2}=(\cos \gamma-3 \cos \alpha \cos \beta)^{2},
$$

where $\alpha$ and $\beta$ are the angles made by the transition dipoles of donor and acceptor in with the line joining the centers of the transitions, and $\gamma$ is the angle between the two transition dipoles. On the other hand Dexter has derived an expression for the rate of EET $\left(k_{\text {Dexter }}\right)$, (6).

$$
k_{\text {Dexter }}=(2 \pi \hbar) K \exp (-2 R / L),
$$

where $K$ is related to specific orbital interactions, $R$ is the distance between the donor and the acceptor molecules, $L$ is an effective average Bohr radius. The orientation dependence of EET seems to be implicit in the orbital interaction parameter $K$.

We note that the Dexter's exchange mechanism requires the presence of electronic communication between the donor and acceptor species (via orbital overlap). However, the ${ }^{1} \mathrm{H}$ NMR and UV-Vis data discussed above indicate that such interaction in these intramolecular porphyrin-anthracene compounds is quite insignificant. Therefore, we chose to analyse the EET in these compounds by the dipole-dipole mechanism as discussed below.

While $J_{\text {Foster }}\left(=1.2 \times 10^{-13} \mathrm{~cm}^{6} \mathrm{mmol}^{-1}\right), \Phi_{D}(=0.24)$ and $\tau_{D}(5.2 \mathrm{~ns})$ are the same for both axially and peripherally substituted situations, the center-to-center distances between the tin(IV) ion and the axial and equatorial anthracene rings of the PM3 minimized structures of these D-A compounds are estimated to be 6.5 and $9.5 \AA$, respectively. Thus, assuming the same value of $\kappa^{2}$ for both axial and equatorial situations and other parameters except $R$ being equal in (4), the Forster energy transfer to the porphyrin should, in principle, be more conducive from the axial anthracenes than it is from the peripheral anthracene. Indeed, for a value of $\kappa^{2}=2 / 3$ (for a random orientation), energy transfer rate from the axial anthracene to the porphyrin has been estimated to be an order of magnitude faster than it is from the peripheral anthracene. This is clearly not the case as revealed by the $k_{\mathrm{EN}}$ (and also $\% T$ ) values given above. Obviously, $\kappa^{2}(5)$ plays a key role in determining the directionality of EET in $\mathbf{3}$. 
Equitable $\kappa^{2}$ values were obtained for the axial and peripheral D-A orientations of the PM3 minimized structures. These structures reveal that, at the axial sites of $\mathbf{3}$ (and also 2), the dihedral angle $\mathrm{Sn}-\mathrm{O}-\mathrm{C}-\mathrm{C}_{\mathrm{anthracene}}$ and the angle $\mathrm{Sn}-\mathrm{O}-\mathrm{C}$ are $165.5^{\circ}$ and $120 \cdot 8^{\circ}$, respectively. The corresponding dihedral angle $\mathrm{C}_{\text {meso }}-\mathrm{O}-\mathrm{C}-\mathrm{C}_{\text {anthracene }}$ and the angle $\mathrm{C}_{\text {meso }}-$ $\mathrm{O}-\mathrm{C}$, at the peripheral sites of $\mathbf{3}$ (and also 1), are $104 \cdot 4^{\circ}$ and $125 \cdot 6^{\circ}$, respectively. While transition dipole of the emitting ${ }^{1} \mathrm{~S}$ state of anthracene lies on the molecule's short axis ${ }^{38}$, that of porphyrin is known to lie along a line joining two opposing pyrrole nitrogens ${ }^{39}$. Using this information and based on the structural data given above, value of $\kappa^{2}$ estimated for the PM3 minimized structure is as low as 0.0004 for the porphyrin-axial anthracene pair and is quite high (1.28) for the porphyrin-peripheral anthracene pair. Given the 'semi-rigid' nature of the linkage between the two chromophores in these systems, our estimation of the magnitudes of the $\kappa^{2}$ values, per se, may not be rigorous. However, this exercise clearly reveals that there is a near perpendicular juxtaposition of the porphyrin and the axial anthracene dipoles in $\mathbf{3}$ (and 2) and a near-coplanar juxtaposition of the porphyrin and the peripheral anthracene dipoles in $\mathbf{3}$ (and 1). The perpendicular orientation of the porphyrin and the axial anthracene subunits in $\mathbf{3}$ is probably due to the fact that the corresponding 'non-perpendicular' orientations are sterically unfavourable in this crowded system. By contrast, changing the dihedral angle between the porphyrin and the equatorial anthracene can potentially generate many energetically-close rotamers that are not sterically unfavourable. In any case, we note that substituting these values of $\kappa^{2}$ in (4) provides a near zero value of $k_{\text {Forster }}$ for the porphyrin-axial anthracene orientation and a non-zero value for the porphyrinperipheral anthracene orientation. Thus, energy transfer is almost negligible from the axial anthracenes in $\mathbf{2}$ and is nearly quantitative from the peripheral anthracene in $\mathbf{1}$. The unique behaviour of compound $\mathbf{3}$, wherein the anthracene donors are connected both at the axial and peripheral sites is thus self explanatory. Notwithstanding this, other explanations (e.g. those involving the tin(IV) centre, through-bond mechanism etc.) that do not invoke the $\kappa^{2}$ dependence of energy transfer and yet rationalise the absence of energy transfer in the axial direction in $\mathbf{2}$ and $\mathbf{3}$ cannot, however, be ruled out altogether.

\section{Conclusions}

In summary, a new family of covalently linked ' $\mathrm{Sn}(\mathrm{IV})$ porphyrin anthracene' diad, triad and tetrad systems, in which the donor anthracene subunits are covalently linked to axial and/or peripheral positions of the porphyrin, have been synthesized and characterized by spectral and electrochemical methods. Energy transfer from the anthracene to the porphyrin has been detected in these systems and EET efficiency is found to be in the order $\mathbf{2}<\mathbf{3}<\mathbf{1}$. The data could be analysed in terms of energy transfer being largely favoured in the peripheral anthracene $\rightarrow$ porphyrin pathway. We believe that realisation of such an orientation dependence of EET would amount to elucidating the unidirectionality of energy transfer - a rarely addressed but significantly useful theme. Indeed, molecular systems (porphyrinic/non-porphyrinic) that exhibit unidirectional electron/energy transfer are much sought after in several research areas of photoscience and molecular electronics. ${ }^{40-43}$

\section{Acknowledgements}

Financial support for this work from the BRNS is gratefully acknowledged. 


\section{References}

1. Ambroise A, Li J, Yu L and Lindsey J S 2000 Org. Lett. 22563

2. Yeow E K L, Sintic P J, Cabral N M, Reek J N H, Crossley M J and Ghiggino K P2000Phys. Chem. Chem. Phys. 24281

3. Osuka A, Shin J-Y, Yoneshima R, Shiratori H, Ohno T, Nozaki K, Nishimura Y, Yamazaki I, Taniguchi S, Shimizu T and Okada T 1999 J. Porphyrins Phthalocyanines 3729

4. Brodard P, Matzinger S, Vauthey E, Mongin O, Papamicaeel C and Gossauer A 1999 J. Phys. Chem. A103 5858

5. Flamigni L, Barigelletti F, Armaroli N, Ventura B, Collin J-P, Sauvage J-P and Williams J A G 1999 Inorg. Chem. 38661

6. Kils K, Kajanus J, Mrtensson J and Albinsson B 1999 J. Phys. Chem. B103 7329

7. Hermant R, Liddell P A, Lin S, Alden R G, Kang H K, Moore A L, Moore T A and Gust D 1993 J. Am. Chem. Soc. 1152080

8. Osuka A, Yamada H, Maruyama K, Mataga N, Asahi O M T, Okada T, Yamazaki I and Nishimura Y 1993 J. Am. Chem. Soc. 1159439

9. Lindsey J S, Brown P A and Siesel D A 1989 Tetrahedron 454845

10. Effenberger F, Schlosser H, Bauerle P, Maier S, Port H and Wolf H C 1988 Angew. Chem., Int. Ed. Engl. 27281

11. Giribabu L, Kumar A A, Neeraja V and Maiya B G 2001 Angew. Chem. (Int. Ed.) 403621

12. Lindsey J S, Schreiman I C, Hsu H C, Kearney P C and Marguerettaz A M 1987 J.Org. Chem. 52827

13. Kadish K M, Xu Q Y, Maiya B G, Barbe J-M and Guilard R 1989 J. Chem. Soc., Dalton Trans. 1531

14. Moghadam G E, Ding L, Tadj F and Meunier B 1989 Tetrahedron 452641

15. Sirish M and Maiya B G 1995 J. Photochem. Photobiol. A88 127

16. Perrin D D, Armarego W LF and Perrin D R 1986 Purification of laboratory chemicals (Oxford: Pergamon)

17. Harriman A and Davila J 1989 Tetrahedron 454737

18. Murov S L 1973 Handbook of photochemistry (New York: Marcel Dekker)

19. Lackowicz J R 1983 Principles of fluorescence spectroscopy (New York: Plenum)

20. Rao T A and Maiya B G 1996 Inorg. Chem. 354829

21. Giribabu L, Rao T A and Maiya B G 1999 Inorg. Chem. 384971

22. Sirish M, Kache R and Maiya B G 1996 J. Photochem. Photobiol. A93 129

23. Giribabu L and Maiya B G 1999 Res. Chem. Intermed. 25769

24. Sirish M and Maiya BG 1998 J. Porphyrins. Phthalocyanins 2327

25. Reddy D R and Maiya B G 2001 Chem. Commun. 117

26. Guilard R, Ratti C, Barbe J M and Kadish K M 1991 Inorg. Chem. 301537

27. Hawley J C $1998 \mathrm{Ph}$ D thesis, University of Cambridge, Cambridge, UK

28. Buchler J W, Puppe L, Rohbock K and Schneehage H H 1973 Chem. Ber. 1062710

29. Singh A K and Roy M 1991 J. Photochem. Photobiol. B8 325

30. Arnold D P and Bartley J P 1994 Inorg. Chem. 331486

31. Abraham R J, Bedford G R, McNeillie D and Wright B 1980 Org. Magn. Reson. 14418

32. Hawley J C, Bampos N, Abraham R J and Sanders J K M 1998 Chem. Commun. 661

33. Nicholson R S and Shain I 1964 Anal. Chem. 36706

34. Kadish K M 1986 Prog. Inorg. Chem. 34435

35. Hirakawa K and Segawa H 1999 J. Photochem. Photobiol. A123 67

36. Forster Th 1959 Discuss. Faraday Soc. 277

37. Dexter D L 1953 J. Chem. Phys. 21836

38. Scholes G D, Ghiggino K P, Oliver A M and Paddon-Row M N 1973 J.Phys. Chem. 9711871

39. Gouterman M 1961 J. Mol. Spectrosc. 6138

40. de Silva A P and Rice T E J 1999 Chem. Commun. 163

41. Fox M A and Galoppini E 1997 J. Am. Chem. Soc. 1195277

42. Sucheta A, Ackreli B A C, Cochran B and Armstrong F 1992 Nature (London) 356361

43. Martin A S and Sambles J R 1996 Nanotechnology 7401 